Journal of Accident and Emergency Medicine 1994 11, 125-126
Correspondence:

D.L. Connolly,

Cardiovascular

Research Group. Department of Medicine, Addenbrookes Hospital, Cambridge CB2 2QQ, UK

\title{
Phaeochromocytoma presenting acutely as severe cardiac failure
}

\author{
D.L. CONNOLLY ${ }^{1}$ and D.A. MARIATHAS ${ }^{2}$ \\ ${ }^{1}$ Department of Cardiology, Papworth Hospital, Cambridge and ${ }^{2}$ Accident and Emergency Medicine, \\ Queen Elizabeth Hospital, King's Lynn
}

\section{INTRODUCTION}

Phaeochromocytoma is a potentially lethal tumour that is surgically curable. It usually presents with hypertension, sweating, palpitations and headache. Acute cardiac failure can occur even in the presence of a normal heart due to massive catecholamine release causing impairment of myocardial function. In this case the diagnosis of phaeochromocytoma was only made at autopsy and illustrates the difficulty in diagnosis unless this unusual but potentially curable form of acute myocardial illness is considered in emergency admissions.

Key words: acute myocardial illness, catecholamine release, phaeochromocytoma, pulmonary oedema

\section{CASE REPORT}

A 43-year-old sports centre manager on holiday in King's Lynn presented to the accident and emergency (A\&E) department at $1500 \mathrm{~h}$ with a 2-h history of severe breathlessness, nausea, epigastric pain and facial tingling. His past medical history included investigation for chest pain at another centre 3 years previously but the patient was unaware of the results of these investigations and no information was available from these sources until later.

On examination he was centrally cyanosed and tachypnoeic with a pulse of 120 beats $\min ^{-1}$ and a blood pressure of $130 / 80 \mathrm{mmHg}$. The jugular venous pressure (JVP) was not raised and the heart sounds were normal but there were coarse crackles throughout both lungs and he was peripherally underperfused.

An ECG showed sinus tachycardia with right axis deviation, right bundle branch block with ST elevation and deep $Q$ waves in leads $V 1$ to $V 3$ suggesting acute anterior myocardial infarction. A chest radiograph showed widespread alveolar infiltration with a normal sized heart. An arterial blood gas on $40 \%$ oxygen showed a $\mathrm{PO}_{2}$ of $6.6 \mathrm{KPa}, \mathrm{aPCO}$ of $6.2 \mathrm{KPa}$ and $\mathrm{a} \mathrm{pH}$ of 7.15 .
An initial diagnosis was made of acute left ventricular failure probably secondary to myocardial infarction. Intravenous frusemide $80 \mathrm{mg}$, diamorphine $5 \mathrm{mg}$ and metoclopramide $10 \mathrm{mg}$ were administered and the patient was transferred to the intensive therapy unit (ITU). Despite $100 \%$ inhaled oxygen the patients oxygen saturation continued to decline and he was ventilated using suxamethonium and etomidate. A full blood count showed a haemoglobin of 16.5 with a raised haematocrit of 0.539 and a mild neutrophilia. A biochemical profile (including amylase and creatinine kinase) was normal except for a glucose level of $23 \mathrm{mmol}^{-1}$. The patient was not known to be diabetic previously and an insulin pump was started.

By $20.00 \mathrm{~h}$ the patient remained unwell with a tachycardia of 120 beats $\min ^{-1}$ and a mild pyrexia of $37.8^{\circ} \mathrm{C}$. Previously, blood pressure had risen to $170 / 100 \mathrm{mmHg}$ after ventilation but was now $100 / 60 \mathrm{mmHg}$. Urine output was minimal despite further intravenous boluses of frusemide. The peripheries remained cold and underperfused. A central line was inserted and measured $+10 \mathrm{~mm}$. SwanGanz catheterization was attempted but the pulmonary artery could not be entered. Dobutamine and low dose dopamine were commenced empirically but the patient's blood pressure continued to fall despite increasing inotropes and he became asystolic $12 \mathrm{~h}$ after admission.

At post mortem there was gross pulmonary oedema with pleural effusions. The left ventricle was dilated and moderately hypertrophied but the coronary arteries were normal and histology was unremarkable. There was a right adrenal tumour of $9 \times 4 \times 3 \mathrm{~cm}$ which, histologically, was a phaeochromocytoma. There were no other abnormalities.

Retrospectively, the patient had been investigated in his home city 3 years previously for occasional episodes of chest pain, sweating, palpitations and facial tingling. An ECG during an episode showed a sinus tachycardia with right bundle branch block 
Phaeochromo-

cytoma: a case report (similar to that subsequently seen on admission to King's Lynn) but was normal afterwards. The systolic blood pressure during an attack was $175 / 115 \mathrm{mmHg}$ but again settled afterwards. Exercise testing, cardiac catheterization, thyroid function tests and a single 24-h urine collection for catecholamines were all normal. The patient had been reassured that it was a paroxysmal conduction abnormality and discharged.

\section{DISCUSSION}

The above case demonstrates that phaeochromocytoma can present with acute cardiac failure and pulmonary oedema despite normal coronary arteries. $^{1}$ Whilst true myocardial infarction can occur, it may also be mimicked by paroxysmal ECG changes. $^{2}$ This may lead to misdiagnosis and inappropriate treatment with a fatal outcome. By reviewing the literature on phaeochromocytoma it is hoped that future similar cases may be correctly diagnosed.

Phaeochromocytoma is a catecholamine secreting tumour of chromaffin cells occurring in 1 to 2 per 100000 adults per year. ${ }^{3}$ Ninety per cent are found in the adrenal medulla and up to $94 \%$ are benign being potentially curable by surgery. Only $10 \%$ have a predisposing familial illness such as neurofibromatosis. Whilst phaeochromocytoma accounts for less than $1 \%$ of all cases of hypertension, between 77 and $98 \%$ of patients with phaeochromocytoma are hypertensive. Paroxysms of severe hypertension lasting minutes to several hours occur in $50 \%$ whilst $80 \%$ suffer episodic palpitations, sweating or headache. During paroxysms hyperglycaemia, hyperthermia and a raised haematocrit may be found. Retrospectively, this patient had many of these features on his previous admission to his home city hospital.

The optimal investigation of patients with suspected phaeochromocytoma is controversial - 24-h urine collection for catecholamines or their metabolites remains standard with a sensitivity of over $76 \%$. However, as this case demonstrates catecholamine release is often episodic and a single measurement can give false security. Sensitivity is improved by repeating the investigation on two or more occasions and especially after a symptomatic paroxysm. ${ }^{4}$ Other useful investigations include a CT or magnetic resonance imaging scan (which visualise $90 \%$ of adrenal phaeochromocytomas) and radio-labelled metaiodobenzylguanidine (MIBG) which is selectively taken up by chromaffin tissue.
Paroxysms of catecholamine release may be precipitated by many drugs including opiates, metoclopramide and suxamethonium. All of these were inadvertently given to this patient. Hypertensive crises after induction of anaesthesia suggests phaeochromocytoma. $^{5}$ Use of dopamine and dobutamine may have worsened the cardiac performance by adding to the excess adrenergic stimulation. Vasoconstriction via increased alpha adrenergic activity may have been worsened by dopamine. Catecholamine excess can also have a direct depressive effect on cardiac function which may be reversible on phaeochromocytoma removal ${ }^{6}$ but cardiac transplantation has been required. ${ }^{7}$

The treatment of a suspected acute paroxysm of catecholamine release from a phaeochromocytoma is intravenous phentolamine $1-5 \mathrm{mg}$. Alpha blockade can cause hypotension but is controllable with saline infusion. After several days of alpha blockade propranolol $10 \mathrm{mg}$ t.d.s. may be added to control tachycardia but only if there is no cardiac failure. Once phaeochromocytoma is proven the patient should be transferred to a specialist centre for surgery where 5 year survival for benign phaeochromocytoma excision exceeds $95 \%$.

\section{REFERENCES}

1. Sardesi S.H., Mourant A.J., Sivathandon Y., Farrow R. \& Gibbons D.O. (1990) Phaeochromocytoma and catecholamine induced cardiomyopathy. British Heart Journal 63, 234-237.

2. Haas G.J., Tzagournis M. \& Boudoulas H. (1988) Pheochromocytoma: catecholamine-mediated electrocardiographic changes mimicking ischaemia. American Heart Journal 116, 1363-1365.

3. Sheps S.G., Jiang N-S, Klee G.G. \& van Heerden J.A. (1990) Recent developments in the diagnosis and treatment of pheochromocytoma. Mayo Clinical Proceedings 65, 88-95.

4. Stein P.P. \& Black H.R. (1990) A simplified approach to the diagnosis of pheochromocytoma. Medicine $\mathbf{7 0}$, 46-66.

5. Dunn E.J., Wolff R.K., Wright C.B., Callard G.M. \& Flege J.B. Jr. (1989) Presentation of undiagnosed pheochromocytoma during coronary artery bypass surgery. Journal of Cardiovascular Surgery $\mathbf{3 0}$, 284-287.

6. Wood R., Commerford P.J., Rose A.G. \& Tooke A. (1991) Reversible catecholamine induced cardiomyopathy. American Heart Journal 121, 610-613.

7. Wilkenfield, C., Cohen M., Lansman S.L., Courtney M., Dische M.R., Pertsemlidis D. \& Krakoff L.R. (1992) Heart transplantation for end stage cardiomyopathy caused by occult pheochromocytoma. Journal of Heart and Lung Transplantation 11, 363-366. 